\title{
A Guide to Selecting Theory to Underpin Information Systems Studies
}

\author{
Sharol Sibongile Mkhomazi ${ }^{1}$ and Tiko Iyamu ${ }^{2}$ \\ ${ }^{1}$ Tshwane University of Technology, Department of Informatics, Pretoria, South Africa \\ mkhomaziss@tut.ac.za \\ ${ }^{2}$ Namibia University of Science and Technology, \\ Department of Business Computing, Windhoek, Namibia \\ connectvilla@gmail.com
}

\begin{abstract}
Empirically or experimental, in every research, methodology (method, approach and technique) are employed. The methodology guides the study from the beginning to the end. What is even more important is how the researcher views and deduces the outcome through his or her analytical lens. Information systems studies are increasingly challenging, primarily because of human interactions with computing. This is mainly due to the fact that human beings are unpredictable, which has impact and influence on how systems are developed, implemented and used.

In the last two decades, researchers of information systems (IS) have begun to employ socio-technical theories (lenses) in their studies. This includes younger and aspiring researchers who strive to understand the importance, as well as the application of the lenses in information systems studies. Selecting appropriate theory to underpin a study is therefore critical, primarily because it shapes and defines the results.

In this article, the factors which influence and determine the selection of theories in IS studies are examined. The aim was not to compare theories that are used to underpin IS studies, rather to understand how the socio-technical theories could provide a systematic method for data analysis in the field. The article also highlights some underpinning theories used in IS studies and their usefulness to researchers seeking to identify a theoretical basis for their arguments.
\end{abstract}

Keywords: Information systems, Research Methodology, Underpinning Theory.

\section{Introduction}

Information systems (IS) discipline is an aspect of computing that continue to involve more of social context in its development and implementation (Avison \& Elliot, 2005). The discipline inculcates sociology of events into computing. The social context in IS makes it more interestingly challenging, whether in the development or implementation stages, including, in the areas of research. Research in IS are carried out primarily to investigate and understand what events happened; why the events 
happened; how did the events happened; and the impact and influence of events in the development, implementation, and use of IS in various environments.

Information systems research is a practical approach to professional inquiry in any social situations and it has become focal in recent times (Agarwal \& Lucas, 2005 ). IS research has expanded significantly and adopted the use of socio-technical theories (Gregor, 2006), many of which are drawn from other disciplines such as sociology. IS research are considered and argued to be practical due to the fact that events are studied in their natural settings, whether through qualitative, quantitative or both methods.

Until recently, fifteen years to be precise, data analysis in IS studies were carried out, using mainly the interpretative approach (Walsham, 1995). This approach by itself is a challenge as it does not have a formula, and it is not guided by distinct views and boundaries (Lawrence, 2010). The argument could be attributed to the fact that people (researchers) often have different opinions and interpretations. Hence, it is useful and critically important to underpin a study with a, or combination of theories. The socio-technical theories are aimed to underpin IS research, meaning it provide guidance from the data collection to empirical data analysis.

However, selecting a theory or combination of theories which is considered to be appropriate to underpin a study is never an easy task by itself. This is a difficult challenge which IS researchers are currently faced with. Many IS researchers are challenged with selecting a theory to underpin their studies. The challenge could be could be attributed to the fact that the theories such as Structuration Theory (ST), Actor Network Theory (ANT), Activity Theory (AT) and Contingency Theory (CT) are not of IS field.

Another critical challenge is that some aspects of the theories could be seen to overlap. The aim of this article is not to compare theories that could be employed in IS research but rather to assist researchers to understand the importance of selecting appropriate theories, and how they could provide a systematic method in data analysis in their studies.

Based on the focus of this article, as stated above, it is important to highlight the role of methodology in IS research. Research methodology encompasses methods, techniques and approaches through which data is collected and analysed. The type of data collected determines the analysis technique that is chosen. The analysis of data provides the end result of the research.

\section{The Role of Research Methodology}

The research methodology consists of methods, techniques and approaches, which provide guidance to research in many fields including IS. According to Zikmund (2003), research methodology is a master plan specifying the methods and procedures for collecting and analysing the needed information. In the same line of argument, Mouton (2001) emphasised that research methodology focuses on the research process and the kind of tools and procedures to be used in achieving the objectives of the study.

In order to achieve the objectives of any research study, a methodology is required. Empirical (or experimental) research methodology comprises a class of methods, 
techniques and approaches in terms of which empirical observations or data are collected in order to answer specific research questions. The empirical research methods are divided into two categories, namely, quantitative and qualitative research methods. According to De Vos, Strydom, Fouche and Delport (2002) quantitative and qualitative research methods are the two well-known and recognised approaches in IS research. The two methods are not in contrast, rather, they complement each another.

Qualitative study is concerned with non-statistical methods. It enable researchers to study social and cultural phenomena Myers (2009). The qualitative research method allows study to be carried out in their natural settings, attempting to make sense of, or interpret phenomena in terms of the meanings people bring to them (Denzin \& Lincoln, 2005). The interpretative nature of a qualitative research study uncovers and describes the actual meanings that people use in real settings (Olivier, 2009). In this article, interpretative is aimed at producing an understanding of the context of IS studies, whereby IS influences and is influenced by its context (Walsham, 1993). The qualitative approach takes social context into considerations in the construction, whether technical and cultural aspects of IS study. It acknowledges that, although IS have a strong technological component, they are implemented and used by people within social context (Modol, 2007).

Alternative to qualitative is the quantitative research method which is aimed to enable researchers to study, also natural phenomena, to measure the social world objectively, as well as to predict and understand human behaviour. De Vos et al (2002) described quantitative method as an inquiry into a social or human problem, based on the testing of a theory composed of variables, measured with numbers and analysed with statistical procedures in order to determine whether the predictive generalisations of the theory hold true. In quantitative, interpretation of numbers is often seen as strong evidence of how a phenomena work or did not work. Based on this premises, it is argued that it is difficult to underpin a numerical data with a theory. This article therefore focuses on selection of theories that underpin qualitative studies.

The role of research methodology is critical as it defines the engineering components of a study through which the objectives are achieved. The methodology defines research attributes such as "What" (strategy), "Where" (design), and "How" a study is carried out. The methodology starts with what type of data and materials are to be collected:

a. What - The type of data and materials to be collected in order to achieve the objectives of the study is strategic in nature. The strategy is fulfilled, through qualitative, quantitative or both methods.

b. Where: This is the design of the study. It determines the entity to be studied, using methods such as the Case Study.

c. How: The "How" attribute defines the techniques or techniques which are employed in the data collection. Data is collected based on the strategy (What) and design (Where) as briefly described above. Analysis is carried out on the collected data. How the analysis is done remain vital and critical stage of any study. 
d. Why: On each of the research methodological steps which are employed in a study, there has to be justifications (WHY). The justification helps to understand the flow and relationship amongst the methods, techniques and approaches. Otherwise, it could be regarded as falsified or lacking bases.

Without a methodology, it will be difficult or impossible to carry out studies which are of rigor, complex or comprehensive in nature. Also, methodology helps to answer questions such as where, when and how the study was conducted, as briefly described above.

Another important factor of the roles of research methodology is the sequence in which the selected methods, techniques and approaches are employed in a study. The importance of this factor is based on the fact that certain actions or events depend on each other. For example, the objectives of a study must be articulated before a decision on whether the study would be qualitative, quantitative or both are reached. Similarly, the qualitative-ness of the study determines the theory that underpins the study. Otherwise, according to Jabar (2009), researchers may not recognise the systematic approach that is provided by theory, in specific steps, during data analysis. Bottomline is that the selection of methods, techniques and how they are applied depend on the aims and objectives of the study, as well as the nature of the phenomenon under investigation.

\section{$3 \quad$ Underpinning Theory}

As already mentioned earlier in this article, in the recent years, IS studies employ socio-technical theories to guide their studies. The use of the theories to underpin studies is mainly in the areas of qualitative interpretive research. This is primarily because of the interplay between technical and non-technical factors which are involved in the field of IS. Underpinning theories are referred to, by Gregor (2002) as theories for understanding social context in IS studies. The theories are intended to explain "how" and "why" things happen in the way that they do.

The theory which underpins a study is often viewed as a lens. In Orlikowski (2000), the word "lens" is used in the sense of assessment, where certain features are focused upon and emerge, and where the rest of the picture falls into the background. Lenses are used as an analytical tool to aid interpretation and analysis of data in research. The analysis of the data determines and shapes the results of the study. The analysis of data is fundamental to any study. Hence, the tool (theory) used in the analysis is deemed critical. How data is collected and analysed is within the frame of the theory which underpin the study.

One of the significance factors of underpinning theories is that they encompass both technical and social contexts within phenomena under study. A theory which underpins a study is characteristically relied upon for rationales such as:

- To help exhume the dependence and relationships which exist among actors within an environment.

- Provides guidance in the interpretation of empirical data which was gathered over time and within a context. 
- Creates awareness of social events, processes and activities which takes place in the development, implementation and practice of information technology and systems.

- $\quad$ Reduces the gap of assumptions and prediction of actions within a context.

The use of socio-technical theory to underpin a study could be viewed as the heart (core) of a research. As shown in Figure 1, the strategy (qualitative in this case) of the research determines the theory which underpin; and the theory helps to shape the result of the research, through its understanding of the socio-technical contexts that are involved.

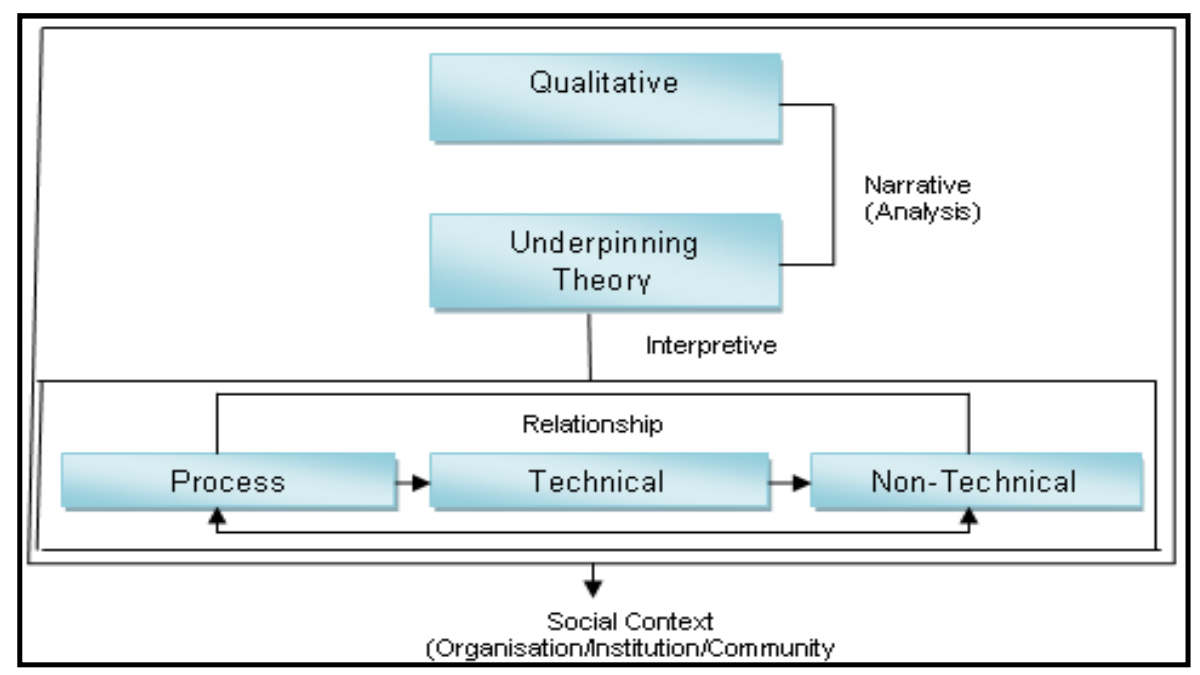

Fig. 1. Research Strategic Approach

As illustrated in figure 1, qualitative research leads itself to narrative description. In this context, narrative is the process of organising the data in units. Roberts (2002) points out that in the process of data analysis it becomes evident that parts of the narrative are not drawn randomly but selected thematically. The data is interpretively analysed using theory, to understand the relationship that exist amongst the core or primary components, which are often Process, Technical and Non-technical. The interpretive analysis of data happens within socio-technical contexts.

The theory which underpins a study is potentially to help find the factors that make a difference either in the development or implementation, or both of information systems in organisations. The aim is to gain better understanding of the socio-technical dynamics in organisations, institutions and how people interact with the systems, so as to solve current or emerging problems. The notion of socio-technical systems is not new. It emerged in the 1950's that through the interaction between people and technology in the course of innovation, socio-technical context do exist (Trist, 1981).

Theories which underpin a study do not predict the outcome of that study. Rather, it enhances our understanding of a situation, and through it, explanation is offered on 
why things happen in the way that they do. The theories make significant contributions to IS research through it's theorises of IS/IT artefacts, particularly from sociotechnical perspectives.

\section{The Use of Underpinning Theory: Success and Failure}

In recent years, reviewers for conferences and journals draw more attentions and emphasis on how results and conclusions are reached in articles. Without underpinning theories, many articles, particularly those based on qualitative data, look speculative or artificial. As a result, for many research articles are not accepted for publication. This is attributed to, mainly two factors: it is either the analysis of the data was not underpinned by theory, or the theory employed was not appropriate. Table 1 is used to illustrate the data that we gather from Information Systems Department from a South African University. This data was collected between 2010 and 2012.

Table 1. The use Underpinning Theory: Success and Failure

\begin{tabular}{|l|l|l|l|}
\hline IS Studies & $\begin{array}{l}\text { Accepted and } \\
\text { Published }\end{array}$ & Not Accepted & Total \\
\hline Underpinning Theory & 38 & 6 & 44 \\
\hline Inappropriate Theory & 9 & 18 & 27 \\
\hline No Underpinning Theory & 7 & 32 & 39 \\
\hline
\end{tabular}

The authors of the articles were both postgraduates and academia. Some of the articles were rewritten, using theories, and appropriately selected. These articles were then accepted and published, thus making significant case for the use of theories in information systems studies.

\section{$5 \quad$ Underpinning Theory and IS Studies}

Theories from sociology discipline has been used by many scholars to underpin a wide range of studies in IS field. Based on the analysis, using socio-technical theories, studies have had theoretical, practical and methodological contributions to the IS field over the years. Some of the theories include Activity Theory, Actor Network Theory, Contingency Theory, Diffusion of Innovation Theory, Grounded Theory and Structuration Theory. Over the years, the use of the theories in IS studies continue to develop.

\section{Activity Theory}

Activity Theory (AT) focuses on human interaction with events and activities within a social context. According to Parks (2000), the theory's investigation of human interaction with others through an activity, forms basic unit of analysis for understanding human behaviour. The theory describes an activity as the way a subject (either an individual or a group) moves towards an object with the purpose of achieving certain 
results or certain objectives. Some of its advantages are that it supports analysis of the dialectic interactions between people; and the ways technologies shapes and are shaped by human activities.

For more than a decade, AT has been a recognised, and arguably know as a theory for enhancing design practices in Computer Supported Collaborative Work (CSCW) and related fields of Human-Computer Interaction (HCI) (Redmiles, 2002). Kuutti (1999) employed AT in a study, to investigate individuals and social transformation in IS development projects; and Demiraslan and Usleul (2008) used AT to examine the integration of technology into Turkish schools.

\section{Actor Network Theory}

Actor Network Theory (ANT) is mainly concern with actors within a heterogeneous network. In ANT, actor is either human or non-human, which seek to make a difference. According to Shin, Choo and Beom (2010), ANT attempt to address power relationship during technology development. As a result of its premises, ANT is often employed to understand why and how technological solutions are created as a carrier of a network of technical and social relations.

ANT has been of IS acceptance for many years (Monteiro \& Hanseth, 1996). The acceptance has led to its use in many studies, such as: the role of standards in innovation and diffusion of broadband mobile service (Yoo, Lyytinen \& Yang, 2005); local actors build broadband infrastructure (Skogseid \& Hanseth, 2005); information infrastructure and rural innovation systems (Skogseid, 2007); and socio-technical dynamics in the development of next generation mobile network (Shin et al., 2010).

\section{Contingency Theory}

Contingency Theory (CT) focuses on situational or environmental factors that influence leadership (Fiedler, 1967). It is an approach to the study of organisational behaviour in which explanations are given as to how contingent factors such as technology, culture and external environment influence the design and function of the environment. The theory claims that there is no single best way to design organisational structure that is effective in some situations, and may not be successful in others (Fiedler, 1967).

Similar to other socio-technical theories discussed herewith, the CT has been applied in many IS studies such as Tinaikar and Flor, (1995); Barki, Rivard. and Talbot (2001); Mathiassen and Sørensen (2007).

\section{Diffusion of Innovation Theory}

Diffusion of Innovation (DOI) is the process by which an innovation is communicated through certain channels over time among the members of a social system (Rogers, 1995). The theory seeks to explain how innovations are undertaken by population within a context. DOI is aimed at making voluntary decisions to accept or reject an innovation which is based on the benefits that they expect to accrue from their own independent use of technology.

The theory has also been applied and adopted in numerous ways. For examples: Blake, Neuendorf and Valdisseri (2005) applied the theory in a study which attempted 
to tailor new websites for online shopping; Bharati and Chandhury (2006) employed the DOI to understand the current status of technology adoption; Hsu, Lu and Hsu (2007) used the theory in their investigation of consumer adoption of internet mobile messaging services (MMS).

\section{Grounded Theory}

Grounded theory develops theory that is grounded in a systematic data gathering and analysis (Jabar, 2009). The theory develops during the research process itself, and is a product of continuous interplay between analysis and data collection (Glaser \& Strauss, 1967). The process involves using multiple stages of data collection and the refinement and interrelationship of categories of information (Strauss \& Corbin, 1998).

Grounded theory has been used in IS studies in real-life contexts, particularly when the boundaries between the phenomenon and its contexts were not seen as being clear, nor were they thought to be clearly defined between the practices of ICT and the organisation. The theory has been applied in IS studies by researchers such as (Orlikowski, 1993) where GT was used to investigate incremental and radical changes in systems development. Hansen and Kautz (2005) used GT to examine how system developers use information systems development methodologies in practice. The GT has proven to be useful in developing context-based, process-oriented descriptions and explanations of information systems phenomena (Goulielmos, 2004).

\section{Structuration Theory}

Structuration Theory (ST) focuses on agent and structure. The theory is concerned with the relationship and interaction between agents and structure. In ST, agents are both technical and non-technical, and structure is rules and resources. According to Iyamu and Roode, (2010), the word 'structure' must not be confused with its obvious connotation of organisational hierarchy in the English language. ST aimed to understand the interplay within social practices across time and space (Giddens, 1984). The action of agent and structure depend on each other, and are produce and reproduce overtime, which is as a result of duality.

The duality of structure consists of three dimensions: Structure, Modality and Interaction. Each of the dimensions contains fundamental elements, Modalities (interpretive schemes, resources and norms); Structure (signification, domination and legitimation); and Interaction (communication, power and sanction). Interaction between agents and structure takes place through the duality of structure, and the interactions produce and reproduce action overtime and space.

\section{Guide to Selecting Underpinning Theories}

This section provide guide for IS researchers in their zeal and quest to selecting theories for their studies. In providing such guidance, the challenges that are often encountered are hereby examined. This is to avoid continuously getting into the pitfall. IS research have drawn on a variety of disciplines including social studies through which underpinning theories act as lenses to explain the phenomenon. IS researchers are 
interested in different theories to underpin their studies. This is primarily to deepen and gain better understanding of the empirical data through analysis.

As discussed in the Underpinning Theory section, theories are significant to IS studies. Theories underpin studies with the primary intention to diffuse the rigor, and examine the socio-technical contexts. Hence the selection of appropriate theory is critical. Otherwise, it could add complexity to the study. However, selection of a theory or combination of theories to underpin a study has never been easy. This could be attributed to many factors such as:

a. Understanding - as mentioned earlier in the article, majority of the theories which are used in IS field originated from sociology discipline. This makes it challenging for IS researchers, in understanding their contexts and focuses.

b. Knowledge - some IS researcher are knowledgeable about a theory. This group of researchers attempt to make use of the particular theory in all the research types that they conduct.

c. Application - many IS researchers (students included) have difficulty on how to apply the social-technical theories in their studies. Experience has shown that even those IS researchers who seem to understand some of the theories, have a challenge in the application.

d. Differentiation - some of the social theories have lots of similarities on their focuses and coverage. Actor network Theory (ANT) and Structuration Theory (ST) are good examples. ANT and ST focuses on Human and nonhuman actors, and technical and non-technical agents, respectively. The focal points of both theories are on Power relationship, and Negotiation of interest within a system.

The emergence of social-technical theories to underpin IS studies have made research more interesting or challenging, depending on the perspective of your fence. The challenge has become very prevalence, and it impacts the space of research activities in IS. This lead to a question that has now become popular amongst IS researchers (students in particular): "what theory can I make use of in my study?" To answer such question, the choice of a theory to underpin an IS study is based on the research objectives, primarily. As such, the objectives must be well articulated and understood. Understanding of the influences and drivers of the objectives is imperative. Also important is having a good understanding of the research problem statement.

When selecting a theory, the researcher need to map the theory to the research objectives and decide which one of the existing theories is suitable for the study. The implication is huge when appropriate theory for the study is not selected. This could result to gaps and disjoint in the findings, thereby hampering the outcome of the research.

The choice of a theory could be subjective. Walsham (2006) offer some tips to researchers in the process of selecting a theory or theories to underpin their studies:

- Do not fix on one theory and then read nothing else

- Do not leave theory generation to the end of your study 
- Do not dismiss a theory's value until you have read about it in some depth

- Do read widely on different theories as this will offer a broader basis on which theory to choose

There is no specific formula for selecting a theory or combination of theories. What are important and helpful are assimilation of the research objectives, and a good understanding of some theories. Understanding of different theories helps the researcher to make appropriate decision.

\subsection{Understanding the Theories}

Table 2 below presents a guide for possible selection of theories to underpin IS studies. The Table consist of the most popular theories that have been used in the IS studies in the last ten years. For each of the theories, a descriptive insight and tenets are provided. The description and tenets are considered as the influencing factors in the selection of the theories for IS studies.

Table 2. Guide to selecting theories

\begin{tabular}{|l|l|l|}
\hline \multicolumn{1}{|c|}{ Theory } & \multicolumn{1}{|c|}{ Description } & \multicolumn{1}{c|}{ Tenets } \\
\hline $\begin{array}{l}\text { Structuration } \\
\text { Theory }\end{array}$ & $\begin{array}{l}\text { Interpretive, narrative, } \\
\text { multi-dimensional }\end{array}$ & $\begin{array}{l}\text { Social context, power relation- } \\
\text { ship, technical, non-technical, } \\
\text { process oriented. }\end{array}$ \\
\hline $\begin{array}{l}\text { Actor Network } \\
\text { Theory }\end{array}$ & $\begin{array}{l}\text { Iterative, Interpretive, } \\
\text { narrative }\end{array}$ & $\begin{array}{l}\text { Power relation, varies interests, } \\
\text { human, non-human, networks, } \\
\text { process oriented. }\end{array}$ \\
\hline $\begin{array}{l}\text { Technology Accep- } \\
\text { tance Model }\end{array}$ & Interpretative, narrative & $\begin{array}{l}\text { Assumption, Presumption, } \\
\text { Human, predictive, Technolo- } \\
\text { gy, Systems }\end{array}$ \\
\hline $\begin{array}{l}\text { Contingency } \\
\text { Theory }\end{array}$ & Interpretative, narrative & $\begin{array}{l}\text { Social context, process oriented, } \\
\text { cultural, human, intents }\end{array}$ \\
\hline Activity Theory & Interpretative, narrative & $\begin{array}{l}\text { Social context, agents relation- } \\
\text { ship, division of labour, process } \\
\text { oriented, }\end{array}$ \\
\hline $\begin{array}{l}\text { Diffusion of Inno- } \\
\text { vation }\end{array}$ & Interpretative, narrative & $\begin{array}{l}\text { Social context, } \\
\text { oriented. }\end{array}$ \\
\hline Grounded Theory & Iterative, Interpretative & $\begin{array}{l}\text { Social context, process } \\
\text { oriented, cultural }\end{array}$ \\
\hline
\end{tabular}

An obvious fact is that the objectives and scope of studies differ in sizes, some are broader than others. In such instances, multiple theories could be required in order to gain full coverage of the data analysis. Also, the theories have the potential to help develop methodological frameworks which are based on a logical appropriation of its tenets and consistent (Avison, Wood-Harper, Vidgen and Wood, 2002). The tenets play a vital role in guiding the analysis of the data. 
There should not be conflict or contradiction in combined use of theories in IS studies. The aim is often not to compare or contrast the theories when they are applied complementarily in a study. According to Iyamu and Roode (2010), the aim is to highlight their importance and complementary usefulness in the research.

In terms of complementarily use of theories, the Moment of translation from the perspective of ANT and duality of structure from the perspective of ST as lenses is good example. The duality of structure could be used to analyse the processes through which legitimating structures evolve and are reconstituted by actions of actors within a system. While Moment of translation could examine how people and objects together operate within a network in heterogeneous processes of translation and negotiations.

ST has also been combined with AT in some IS studies. Hussain, Taylor and Flynn (2004), applied ST and AT complementarily in their study, which resulted to the development of legitimation activity model (LAM). Widjaja and Balbo (2005) employed both ST and AT to understand human activity in the larger social context.

\section{Conclusion}

The number of social-technical theories is growing, so is their use IS studies. The use of theories to underpin studies bring a fresh perspectives into IS research. IS research is gradually becoming more dynamic rather than the traditional stagnant approaches, which are of the direct interpretive of data and statistical methods.

However, the use of the social-technical theories could be detrimental if they are not understood or appropriately selected, and applied. This article presents the importance and implication of understanding the theories before selection; and a guide on the influence and how a theories or theories could be selected to underpin IS studies. These are the primary contributions of the article.

\section{References}

Agarwal, R., Lucas, H.C.: The Information Systems Identity Crisis: Focusing on HighVisibility and High-Impact Research. MIS Quarterly 29(3), 381-398 (2005)

Avison, D., Elliot, S.: Scoping the discipline of Information Systems. In: Avi-son, D.E., PriesHeje, J. (eds.) Research in Information Systems: A Handbook for Research Supervisors and their Students (2005)

Avison, D.E., Wood-Harper, A.T., Vidgen, R., Wood, J.R.G.: A Further Explora-tion into Information Systems Development: The Evolution of Multiview2. Information Technology and People 11(2), 124-139 (2002)

Barki, H., Rivard, S., Talbot, J.: An integrative contingency model of software project risk management. Journal of Management Information System 17(4), 37-69 (2001)

Bharati, P., Chandhury, A.: Current status of technology adoption: Micro, small and medium manufacturing firms in Boston. Communications of the ACM 49(10), 88-93 (2006)

Blake, B.F., Neuendorf, K.A., Valdisseri, C.M.: Tailoring new websites to appeal to those most likely to shop online. Technovation 25(10), 1205-1214 (2005)

De Vos, A.S., Strydom, H., Fouche, C.B., Delport, C.S.L.: Research at Grass Roots: For the social sciences and human service professions. Van Schaik, Pretoria (2002) 
Demiraslan, Y., Usleul, Y.: ICT integration in Turkish schools: Using activity theory to study issues and contradictions. Australasian Journal of Educational Technology 24(4), 458-474 (2008)

Denzin, N.K., Lincoln, Y.S.: The SAGE handbook of qualitative research, 3rd edn. Sage Publications, London (2005)

Fiedler, F.E.: A theory of leadership effectiveness. McGraw-Hill, New York (1967); Gregor, S.: The Nature of Theory in Information Systems. MIS Quarterly 30(3), 611-642 (2006)

Giddens, A.: The Constitution of society: Outline of the theory of Structuration. University of California Press, Berkely (1984)

Glaser, B.G., Strauss, A.L.: The Discovery of Grounded Theory. Aldine press, Chicago (1967)

Goulielmos, M.: Systems development approach: transcending methodology. Information Systems Journal 14, 363-386 (2004)

Gregor, S.: A theory of theories in Information Systems. In: Gregor, S., Hart, D. (eds.) Information Systems Foundations: Building the Theoretical Base, pp. 1-20. Australian Univeristy, Cnberra (2002)

Hansen, B., Kautz, K.: Grounded Theory Applied - Studying Information Systems Development Methodologies in Practice. Paper Presented in the Proceedings of the 38th Hawaii International Conference on System Sciences. IEEE (2005)

Hsu, C.L., Lu, H.P., Hsu, H.H.: Adoption of the mobile internet on empirical study of multimedia message service (MMS), OMEGA. International Journal of Management Science 35(6), 715-726 (2007)

Hussain, Z., Taylor, A., Flynn, D.: A case study of the process of achieving legitimation in information systems development. Journal of Information Science 30(5), 408-417 (2004)

Iyamu, T., Roode, D.: The Use of Structuration Theory and Actor Network Theory for Analysis: Case Study of a Financial Institution. International Journal of Actornetwork Theory and Technological Innovation 2(1), 1-17 (2010)

Jabar, M.A.: An investigation into methods and concepts of qualitative research in Information Systems research. Computer and Information Science Journal 2(4), 47-54 (2009)

Kuutti, K.: Activity Theory, transformation of work, and information systems design. In: Engeström, Y., Miettinen, R., Punamäki-Gitai, R.L. (eds.) Perspectives on Activity Theory, pp. 360-376. Cambridge University Press, New York (1999)

Lawrence, J.: The factors that influence adoption and usage decision in SMEs: Evalu-ating interpretive case study research in information systems. The Electronic Journal of Business Research Methods 8(1), 51-62 (2010)

Mathiassen, L., Sørensen, C.: A theory of organizational information service, Working paper series (2007)

Modol, J.R.: Exploring the standardisation and intergration in the implementation of Industry interorganisational Information Systems: A Case Study in the Seaport of Barcelona (2007)

Monteiro, E., Hanseth, O.: Social Shaping of Information Infrastructure. In: Orlikowski, W.J., Walsham, G., Jones, M., De Gross, J.I. (eds.) Information Technology and Changes in Organisational Work. Chapman and Hall, London (1996)

Mouton, J.: How to succeed in your master's and doctoral studies: a South African guide and resource book. Van Schaik, Pretoria (2001)

Myers, M.D.: Qualitative research in Business \& Management. Sage Publication, London (2009)

Olivier, M.S.: Information Technology research: A practical guide for Computer Science and Informatics, 3rd edn. Van Schaik, Pretoria (2009)

Orlikowski, W.J.: Case tools as organisational change: Investigating incremental and radical changes in Systems Development. MIS Quaterly 17(3), 309-340 (1993) 
Orlikowski, W.J.: Using technology and constituting structures: a practice lens for studying technology in organisations. Organisational Science 11(4), 404-428 (2000)

Parks, S.: Same task, different activities: Issues of investment, identity and use of strategy. TESL Canada Journal 17(2), 64-88 (2000)

Redmiles, D.: Introduction to the special issue on activity theory and the practice of design. Computer Supported Cooperative Work 11(1), 1-11 (2002)

Roberts, C.: Biography research. Open University Press, Buckingham (2002)

Rogers, E.M.: Diffusion of Innovations. The Free Press, New York (1995)

Shin, D.H., Choo, H., Beom, K.: Socio-technical dynamics in the development of Next Generation Mobile Networks Moments of Translation Processes of Beyond 3G. Technological Forecasting and Social Change 75(9), 1406-1415 (2010)

Skogseid, I.: Information infrastructure and rural innovation systems: A study of the dynamics of local adaptation of ICT. University of Olso, Norway (2007)

Skogseid, I., Hanseth, O.: Local actors build broadband infrastructure. Paper presented in the Proceedings of the 13th European Conference on Information Systems, ECIS 2005, 16971708 (2005)

Strauss, A., Corbin, J.: Basics of qualitative research: Grounded theory procedures and techniques. Sage Publication, Newbury (1998)

Tinaikar, R., Flor, P.R.: Towards a contingency theory of control in information systems development projects. Producão 5(1), 5-22 (1995)

Trist, E.: The evolution of socio-technical systems: A conceptual framework and an action research program. Issues in the Quality of Working Life 2 (1981)

Walsham, G.: Interpreting Information Systems in Organisations. John Wiley \& Sons, Chichester (1993)

Walsham, G.: Interpretive case studies in IS research: Nature and Method. European Journal of Information Systems, 74-81 (1995)

Walsham, G.: Doing interpretative research. European Journal of Information Systems 15(3), 320-330 (2006)

Widjaja, I., Balbo, S.: Structuration of Activity: a view on human activity. Paper Presented at the Proceedings of OZCHI 2005 of the 17th Australia Conference on Computer-Human Interaction: Citizens Online: Consideration for Today and the Future, Australia (2005)

Yoo, Y., Lyytinen, K., Yang, H.: The role of standards in innovation and diffusion of broadband mobile services: The case of South Korea. The Journal of Strategic Information Systems 14(3), 323-353 (2005)

Zikmund, W.G.: Business research methods, 7th edn. Thompson South Western, Ohio (2003) 